\title{
Effect of Abutment Height and Cement Thickness on the Retention of
}

\section{Cement-Retained Implant-Supported Restorations}

\author{
Alaa Abou-Obaid ${ }^{1 *}$ and Reem Al-Khudairy ${ }^{2}$ \\ ${ }^{1}$ Department of Prosthetic Dental Sciences, King Saud University, Saudi Arabia \\ ${ }^{2}$ Prosthodontist, Al Yamamh Hospital, Ministry of Health, Saudi Arabia
}

Submission: July 02, 2018; Published: August 20, 2018

*Corresponding author: Alaa Abou Obaid, Lecturer, Department of Prosthetic Dental Sciences, College of Dentistry, King Saud University, Saudi Arabia, Riyadh, Email: aiabuobaid@ksu.edu.sa

\begin{abstract}
Objective: To evaluate the effect of abutment height and cement film thickness on the retention of cement-retained implant-supported restorations.

Materials and methods: A total of 20 implant assemblies were randomly divided into equal groups of ten each according to the abutment height $(5.5 \mathrm{~mm}, 3 \mathrm{~mm})$. Thirty CAD/CAM zirconia copings were fabricated for each abutment height. These copings were sub-divided into 3 groups according to the tested cement film thickness $(20 \mu \mathrm{m}, 35 \mu \mathrm{m}, 50 \mu \mathrm{m})$. Each coping was cemented with a provisional cement (Temp Bond). Twenty-four hours after cementation, the specimens were thermocycled for 500 cycles and subjected to pull-out test. The tensile strength of each specimen was recorded in $(\mathrm{N})$.

Results: The highest mean values of tensile strength for the standard and shortened abutments were (87.83N) and (63.23N) respectively, noticed with the $20 \mu \mathrm{m}$ cement film thickness. While the lowest mean values were detected with the $35 \mu \mathrm{m}$ cement thickness (68.83N) for the standard abutments and $(49.59 \mathrm{~N})$ with the $50 \mu \mathrm{m}$ for the shortened abutments. For both abutment heights, the $20 \mu \mathrm{m}$ cement film thickness significantly differed than the other groups. However, no significant differences was found between $35 \mu \mathrm{m}$ and $50 \mu \mathrm{m}$ cement film thickness $(P>0.05)$. Standard abutments showed a significantly greater retentive forces compared to shortened abutments with each cement thickness $(\mathrm{P}<0.05)$.

Conclusion: Cement thickness of $20 \mu \mathrm{m}$ has a significant effect on the retention of cement-retained single implant restorations with standard or shortened abutment heights. However, the increase in cement thickness from $35 \mu \mathrm{m}$ and $50 \mu \mathrm{m}$ has no effect on the retention of the restoration. Keywords: Implant; Abutment height; Cement thickness; Retention; Cement-retained restoration
\end{abstract}

\section{Introduction}

The prosthetic treatment options to replace missing teeth have rapidly changed to include dental implants as a standard of care and the optimal treatment choice in most cases due to their obvious advantage of preservation of the adjacent tooth structure $[1,2]$. Dental prosthetic reconstructions can be fixed to an implant either by screw-retained or cement-retained. The choice of either retention type depends on various factors such as retrievability, passivity, occlusion, and esthetics. Both retention types have their advantages. A screw-retained dental prostheses is retrievable without restoration being destroyed. This is especially true, for long span restoration with higher risk of complication [3]. On the other hand, cements when used appropriately can also provide retrievability [4]. Cement-retained prostheses have clinical advantages of the compensation of improperly inclined implants, improved esthetic due to absence of screw access hole, greater passivity of fit due to the cement layer between the implant abutment and reconstruction, less incidence of ceramic veneer fracture, intact occlusal table specially for posterior narrow diameter implant, better stress distribution and reduced cost and complexity of laboratory procedures [5-9]. Furthermore, challenges with accessibility placing the screw driver of screwretained restoration in patient with a limited opening and/or in the posterior area can be eliminated using cement-retained prostheses [10].

Cement-retained implant-supported prostheses are widely used as a retention type. Abutment preparation designs and cementation techniques can mimic conventional fixed prosthodontic procedures. Same as natural teeth, abutment geometry such as height and taper influence the retention. The retention is proportional to height and inversely proportional to taper $[8,11]$. 
Cementation of the implant prostheses allows the clinician to optimize the fit on the implant abutment. A provisional luting agent may be used as a final luting agent when retrievability is a major concern [4]. A weak luting agent has been suggested to be used at first, progressing to stronger cements until the desired amount of retention has been achieved [12]. It is widely accepted that cement thickness is also a factor affecting the durability of the cement, leading to retention of the restoration [13]. However, inadequate cement space resulted in crown seating discrepancy [14]. Ideal taper and long walls of implant abutment increases the retention of a given restoration [15]. However, there is not enough evidence support the ideal cement thickness for retrievability and the anticipated amount of retention when less than ideal situation is encountered where abutment hight modification was necessary.

The purpose of this study was to investigate the effect of abutment height and amount of film thickness of luting agent on the retentive strength of cement-retained implant restorations. The null hypothesis was that there would be no significant difference in the retention of cemented crowns on intact implant abutments or those that have lost length with different amount of film thickness.

\section{Materials and Methods}

\section{Specimen preparation}

A total of twenty implant fixtures measuring $4.1 \mathrm{~mm} \times 12 \mathrm{~mm}$
(Standard plus implant [ITI system, Straumann AG, Basel, Switzerland]) were mounted with epoxy resin-glass fiber composite (NEMA Grade G-10 rod, Piedmont Plastics, Charlotte, $\mathrm{NC}$ ) in cylinders measuring $25 \mathrm{~mm}$ in length and $35 \mathrm{~mm}$ in diameter using a dental surveyor (J.M. Ney Co., Bloomfield, CT, USA) to ensure a straight and parallel placement of the implants. The implant fixtures were randomly divided into two equal groups of ten each according to the different implant abutment height used. The control group consisted of implant fixtures with a standard $5.5 \mathrm{~mm}$ synocta abutments (048.605 ITI system, Straumann AG, Basel, Switzerland). In the second group, the abutment heights were shortened up to $3 \mathrm{~mm}$.

\section{Fabrication of the copings}

Fabrication of the copings were done using the computer-aided design and computer-aided manufacturing (CAD/CAM) technique. The abutments were scanned with optical scanner (Cercon eye; Dentsply, Germany) to fabricate thirty zirconia copings (Cercon Base; Degudent, Dentsply, York, PA) for each abutment height. Then, the copings were sub-divided into 3 groups according to the tested cement film thickness $(20 \mu \mathrm{m}, 35 \mu \mathrm{m}, 50 \mu \mathrm{m})$. The copings were designed with two wings in the proximal surfaces to secure the restoration into a customized jig to be used during the pull-out test (Figure 1). All copings were air-abraded with $50 \mu \mathrm{m}$ alumina particles at $0.25 \mathrm{MPa}$.
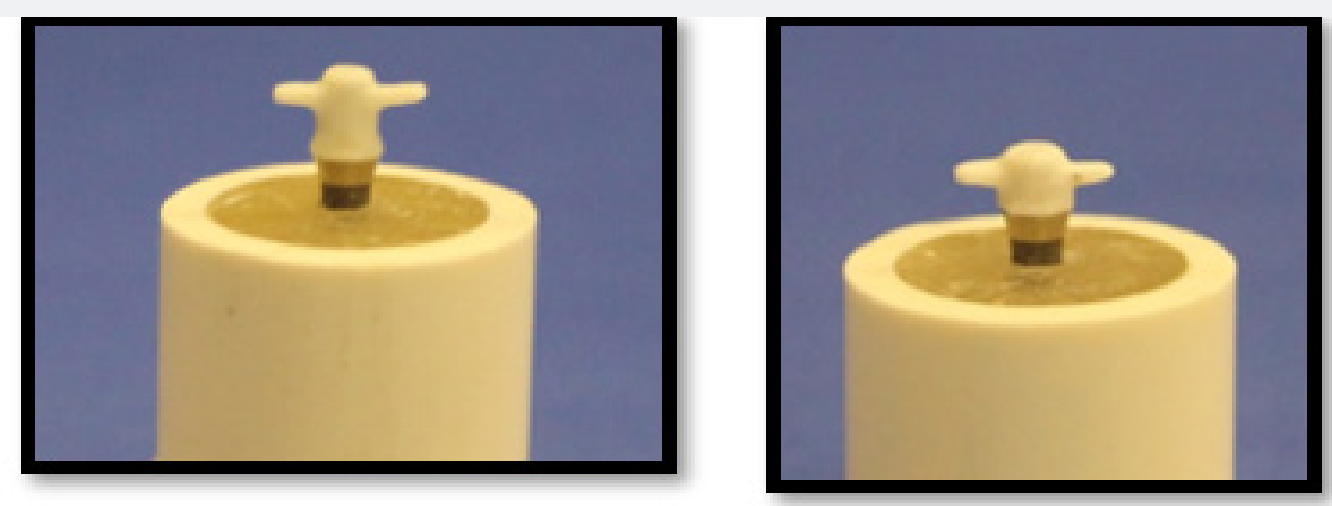

Figure 1: Cemented copings on standard and shortened abutment heights.

\section{Cementation of the copings}

Before cementation, each screw-retained abutment was tightened to the recommended torque $(35 \mathrm{Ncm})$ and then retightened (to the same torque value) 10 minutes later to minimize embedment relaxation between the mating threads. The abutment screw access opening was covered with vinylpolysiloxane impression material (Virtual, Refill light body, Regular set wash material, Ivoclar vivadent, Italy) to prevent the excess of cement from escaping to the screw access hole. A provisional cement was used to fix the copings with the abutments (Temp Bond cement, Kerr, Italy) and a calibrated syringe was used to place a standardized increment of the cement $(0.1 \mathrm{~mL})$ in each coping. Then, each coping was placed on the abutment with finger pressure for 10 seconds. Excess cement was removed with dental explorer and the specimen was loaded on its long axis with a $2 \mathrm{~kg}$ weight for 5 minutes. This procedure was carried out by one investigator.

Twenty-four hours after cementation, the specimens were thermocycled between $5{ }^{\circ} \mathrm{C}$ and $55^{\circ} \mathrm{C}$ with 10 -second dwell times for 500 cycles (Thermocycler THE-1100, SD Mechatronik GMBH, Feldkirchen-Westerham, Germany).

\section{Testing procedure}

After thermocycling, each specimen was vertically secured in the universal testing machine (Instron 8500; Instron Corp, Norwood, MA) and subjected to a pull-out test at a $0.5 \mathrm{~mm} / \mathrm{min}$ crosshead speed (Figure 2). The load required for dislodgment of the coping was recorded in $(\mathrm{N})$. 


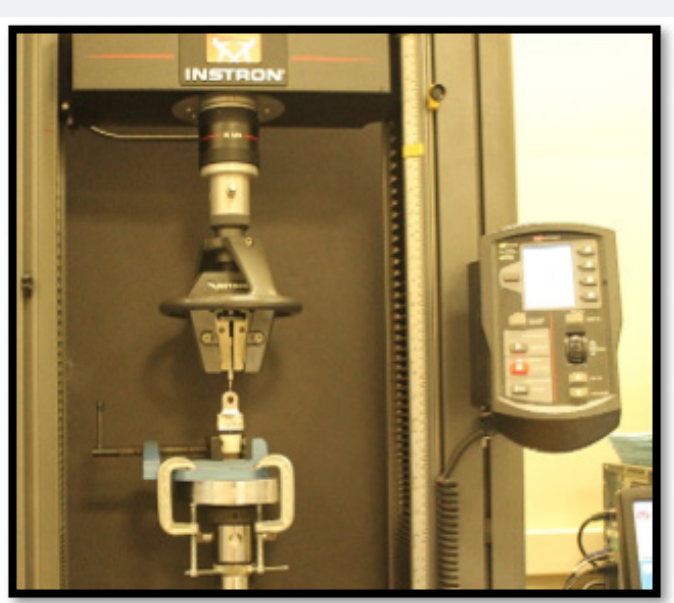

Figure 2: A Specimen loaded in the universal testing machine (Instron).

\section{Statistical analysis}

The statistical tests were performed using the SPSS 16.0 program (SPSS Inc., Chicago, IL, USA). The data was analyzed using two and one-way analysis of variance (ANOVA) and independent t-test. All statistical analysis was performed at 0.05 level of significance.

\section{Results}

Table 1 shows the mean uniaxial retention force, standard deviation and standard error for each group. Two-way ANOVA (Table 2) revealed significant differences in the retention force with different abutment heights, cement thicknesses and the interaction between these two factors $(\mathrm{P}<0.05)$.

Table 1: Mean ( \pm std. deviation) and std. error of uniaxial tensile strength for each group.

\begin{tabular}{|c|c|c|c|}
\hline Abutment height & Cement thickness & Mean + Std. Deviation & Std. Error \\
\hline \multirow{3}{*}{ Standard (5.5mm) } & $20 \mu \mathrm{m}$ & $87.83(4.17)$ & 1.32 \\
\cline { 2 - 4 } & $35 \mu \mathrm{m}$ & $68.83(5.53)$ & 1.75 \\
\cline { 2 - 4 } & $50 \mu \mathrm{m}$ & $69.39(2.11)$ & 0.67 \\
\hline \multirow{3}{*}{ Shortened (3mm) } & $20 \mu \mathrm{m}$ & $63.23(3.38)$ & 1.07 \\
\cline { 2 - 4 } & $35 \mu \mathrm{m}$ & $52.67(3.39)$ & 1.07 \\
\cline { 2 - 4 } & $50 \mu \mathrm{m}$ & $49.59(1.05)$ & 0.33 \\
\hline
\end{tabular}

Table 2: Two-way ANOVA results for uniaxial retention force of the cemented copings.

\begin{tabular}{|c|c|c|c|c|c|}
\hline Source & $\begin{array}{c}\text { Type III Sum of } \\
\text { Squares }\end{array}$ & df & Mean Square & F & Sig. \\
\hline Corrected Model & 9476.46 & 5 & 1895.29 & 148.904 & 0.000 \\
\hline Intercept & 255494 & 1 & 255494 & 20072.9 & 0.000 \\
\hline Height & 6113.53 & 1 & 6113.53 & 480.311 & 0.000 \\
\hline Thickness & 3183.55 & 2 & 1591.77 & 125.058 & 0.000 \\
\hline Height*Thickness & 179.378 & 2 & 89.689 & 12.728 & \\
\hline Error & 687.328 & 54 & & & \\
\hline Total & 265658 & 60 & & & \\
\hline Corrected Total & 10163.8 & 59 & & & \\
\hline
\end{tabular}

For the standard and shortened abutments, the highest mean values of tensile strength were $(87.83 \mathrm{~N})$ and $(63.23 \mathrm{~N})$ respectively, noticed with the $20 \mu \mathrm{m}$ cement film thickness. While the lowest mean values were detected with the $35 \mu$ m cement thickness $(68.83$ $\mathrm{N})$ for the standard abutments and with the $50 \mu \mathrm{m}(49.59 \mathrm{~N})$ for the shortened abutments (Figure 3). One-way ANOVA demonstrated statistically significant differences in the tensile strength among different cement thicknesses in each abutment height $(\mathrm{P}=0.00)$. Tukey Post Hoc test for multiple comparison showed a significant difference in the mean of the uniaxial tensile strength noticed between the $20 \mu \mathrm{m}$ cement film thickness compared to the other groups $(\mathrm{P}=0.00)$ for standard and shortened abutments. However, no significant differences were found between $35 \mu \mathrm{m}$ and $50 \mu \mathrm{m}$ cement film thickness for both abutment heights $(\mathrm{P}>0.05)$. Independent sample t-test showed that standard abutments had a significantly greater retentive forces compared to shortened abutments with each cement thickness $(\mathrm{P}<0.05)$. 


\section{Advances in Dentistry \& Oral Health}

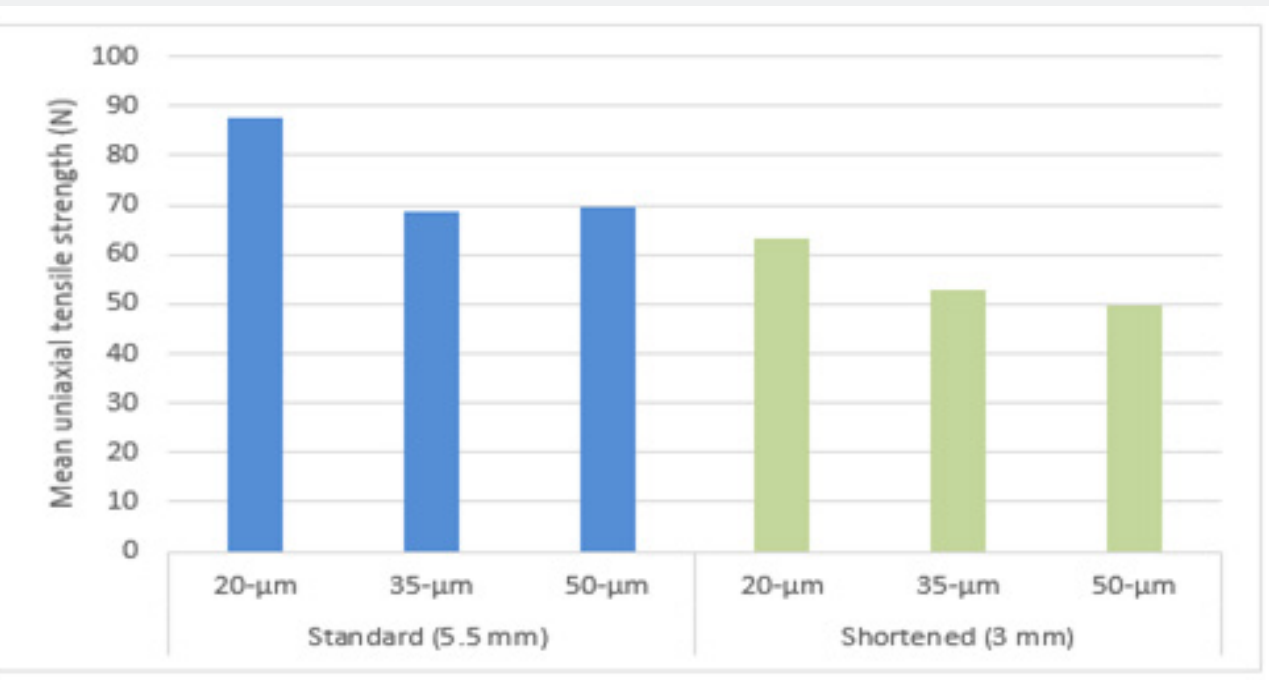

Figure 3: Mean uniaxial tensile strength for the tested groups.

\section{Discussion}

The retention of cement-retained implant-supported restoration plays an important role in the success of treatment. Cemented restorations can compensate for minor fit discrepancies using a luting agent [16]. Nevertheless, in some clinical studies, retention loss found to be frequently occurring complication $[17,18]$. Therefore, it is clinically important to understand how to manage abutment geometry in relation to retrievable weaker luting cement and appropriate cement thickness to provide the adequate amount of retention in case of a clinically compromised situation. The results of this study rejected the null hypothesis, since the retention of cement-retained implant-supported restorations were significantly affected by the abutment height and cement space.

During fabrication of implant-supported restoration, distortion might occur at any stage due to casting and investing procedures $[19,20]$. Therefore, CAD/CAM technique was used to ensure standardization of the fabrication of all coping specimens. Luting agents' tensile bond strength may be affected by variation in mixing. Conventional mixing method may also risk the mixing ratio. Thus, lowers cement quality. In this study, cement was applied using syringe dispenser to calibrate the amount of cement used.

Cement thickness is one of the factors affecting the durability of the cement. However, when cement space is inadequate, it will result in crown seating discrepancies. The cement space helps to improve seating of a crown, reduces the elevation of restorations, improves the outflow of excess cement, and lowers the seating forces, resulting in a better fit and retention of the final restoration $[13,21,22]$. In this study, three cement space parameters were used; $20 \mu \mathrm{m}$, which is consistent with ADA specification \#96 for ideal cement thickness, $50 \mu \mathrm{m}$ according to several investigations that apply this cement thickness [23,24] and midway between these was applied $(35 \mu \mathrm{m})$.
The data of this study showed that the retention of the zirconia coping was influenced by the geometry of the abutments, this agrees with dental literature $[16,25,26]$. Cano-Batalla et al. found a significant difference in crown retentions when comparing the heights of 4,5, and $6 \mathrm{~mm}$ of cylindrical pre-fabricated abutments [27]. In this study, the height of $5.5 \mathrm{~mm}$ produced significantly higher retention when compared with a reduced height of $3 \mathrm{~mm}$. Regardless of abutment height, cement space of $20 \mu \mathrm{m}$ was statistically significant more retentive compared to other cement spaces. Whereas, cement spaces of $35 \mu \mathrm{m}$ and $50 \mu \mathrm{m}$ had no significant differences. The finding of this study agreed with the finding of another study by Gultekin et al. who reported that increasing the cement space from 20 to $40 \mu \mathrm{m}$ for the lower strength cements did not have any significant effect on retention [22]. The result of this study contradicts the findings by El-Anwar et al. who recommended increasing the cement layer thickness regardless of cement type for longer life-time crown fixation [28]. It can be inferred that weaker cements need less cement space gap as increasing beyond certain number might affect the strength of restoration without significantly improving marginal fit [29]. Weak cement was suggested to be effective to enable restoration retrieval [30]. However, when retention of the abutment is compromised by loss of height, a stronger luting cement may be indicated [27]. It is important to weigh the clinical need for retrieval against retention.

The Limitation of the study was the lack of evaluation of mechanical cycling that simulate the dynamic loading with a combination of compressive and tensile stresses on the restoration during mastication, only a tensile force is applied for restoration retrievability. Another limitation was the use of one type of luting cement. Different results could have been obtained if different cements were used.

\section{Conclusion}

Within the limitation of this study, the following conclusion can be drawn: 
Cement thickness of $20 \mu \mathrm{m}$ has a significant effect on the retention of cement-retained restorations while, the increase in cement thickness from $35 \mu \mathrm{m}$ and $50 \mu \mathrm{m}$ has no effect on the retention of single implant restoration with standard or shortened abutment heights.

\section{Acknowledgement}

The authors would like to thank the College of Dentistry Research Center and Deanship of Scientific Research at King Saud University, Saudi Arabia for supporting this research project (FR0380). The authors are also gratefully acknowledging the help of Mr. Nassr Al Moflehi, Biostatistician Consultant, College of Dentistry, King Saud University.

\section{References}

1. Adell R, Lekholm U, Rockler B, Brånemark PI (1981) A 15-year study of osseointegrated implants in the treatment of the edentulous jaw. Int J Oral Surg 10(6): 387-416.

2. Newman MG (1999) The single-tooth implant as a standard of care. Int J Oral Maxillofac Implants 14(5): 621-622.

3. Salvi GE, Brägger U (2009) Mechanical and technical risks in implant therapy. Int J Oral Maxillofac Implants 24 Suppl: 69-85.

4. Breeding LC, Dixon DL, Bogacki MT, Tietge JD (1992) Use of luting agents with an implant system: Part I. J Prosthet Dent 68(5): 737-741.

5. Schweitzer DM, Berg RW, Mancia GO (2011) A technique for retrieval of cement-retained implant-supported prostheses. J Prosthet Dent 106(2): 134-138.

6. Wittneben JG, Millen C, Brägger U (2014) Clinical performance of screw- versus cement-retained fixed implant-supported reconstructions-a systematic review. Int J Oral Maxillofac Implants 29 Suppl: $84-$ 98.

7. Ma S, Fenton A (2015) Screw-versus cement-retained implant prostheses: a systematic review of prosthodontic maintenance and complications. Int J Prosthodont 28(2): 127-145.

8. Maeyama H, Sawase T, Jimbo R, Kamada K, Suketa N, et al. (2005) Retentive strength of metal copings on prefabricated abutments with five different cements. Clin Implant Dent Relat Res 7(4): 229-234.

9. Wittneben JG, Joda T, Weber HP, Brägger U (2017) Screw retained vs. cement retained implant-supported fixed dental prosthesis. Periodontol 2000 73(1): 141-151.

10. Chee W, Jivraj S (2006) Impression techniques for implant dentistry. Br Dent J 201(8): 429-432.

11. Ramp MH, Dixon DL, Ramp LC, Breeding LC, Barber LL (1999) Tensile bond strengths of provisional luting agents used with an implant system. J Prosthet Dent 81(5): 510-514.

12. Hebel KS, Gajjar RC (1997) Cement-retained versus screw-retained implant restorations: achieving optimal occlusion and esthetics in implant dentistry. J Prosthet Dent 77(1): 28-35.

13. Eames WB, O Neal SJ, Monteiro J, Miller C, Roan JD, et al. (1978) Techniques to improve the seating of castings. J Am Dent Assoc 96(3): 432437.

14. Wu JC, Wilson PR (1994) Optimal cement space for resin luting cements. Int J Prosthodont 7(3): 209-215.
15. Al Hamad KQ Al Rashdan BA, Abu-Sitta EH (2011) The effects of height and surface roughness of abutments and the type of cement on bond strength of cement-retained implant restorations. Clin Oral Implants Res 22(6): 638-644.

16. Bernal G, Okamura M, Muñoz CA (2003) The effects of abutment taper, length and cement type on resistance to dislodgement of cement-retained, implant-supported restorations. J Prosthodont 12(2): 111-115.

17. Nedir R, Bischof M, Szmukler-Moncler S, Belser UC, Samson J (2006) Prosthetic complications with dental implants: from an up-to-8-year experience in private practice. Int J Oral Maxillofac Implants 21(6): 919-928.

18. Wennström JL, Ekestubbe A, Gröndahl K, Karlsson S, Lindhe J (2005) Implant-supported single-tooth restorations: a 5 -year prospective study. J Clin Periodontol 32(6): 567-574.

19. Santosa RE, Martin W, Morton D (2010) Effects of a cementing technique in addition to luting agent on the uniaxial retention force of a single-tooth implant-supported restoration: an in vitro study. Int J Oral Maxillofac Implants 25(6): 1145-1152.

20. Mehl C, Harder S, Wolfart M, Kern M, Wolfart S (2008) Retrievability of implant-retained crowns following cementation. Clin Oral Implants Res 19(12): 1304-1311.

21. Squier RS, Agar JR, Duncan JP, Taylor TD (2001) Retentiveness of dental cements used with metallic implant components. Int J Oral Maxillofac Implants 16(6): 793-798.

22. Gultekin P, Gultekin BA, Aydin M, Yalcin S (2013) Cement selection for implant-supported crowns fabricated with different luting space settings. J Prosthodont 22(2): 112-119.

23. Wadhwani C, Piñeyro A, Hess T, Zhang H, Chung KH (2011) Effect of implant abutment modification on the extrusion of excess cement at the crown-abutment margin for cement-retained implant restorations. Int J Oral Maxillofac Implants 26(6): 1241-1246.

24. Yuzbasioglu E (2014) A modified technique for extraoral cementation of implant retained restorations for preventing excess cement around the margins. J Adv Prosthodont 6(2): 146-149.

25. Mansour A, Ercoli C, Graser G, Tallents R, Moss M (2002) Comparative evaluation of casting retention using the ITI solid abutment with six cements. Clin Oral Implants Res 13(4): 343-348.

26. Bresciano M, Schierano G, Manzella C, Screti A, Bignardi C, et al. (2005) Retention of luting agents on implant abutments of different height and taper. Clin Oral Implants Res 16(5): 594-598.

27. Cano-Batalla J, Soliva-Garriga J, Campillo-Funollet M, Munoz-Viveros CA, Giner-Tarrida L (2012) Influence of abutment height and surface roughness on in vitro retention of three luting agents. Int J Oral Maxillofac Implants 27(1): 36-41.

28. El-Anwar MI, Tamamb RA, Fawzyc UM, Yousiefde SA (2015) The effect of luting cement type and thickness on stress distribution in upper premolar implant restored with metal ceramic crowns. Tanta Dental Journal 12(1): 48-55.

29. Silva NR, Witek L, Coelho PG, Thompson VP, Rekow ED, et al. (2011) Additive CAD/CAM process for dental prostheses. J Prosthodont 20(2): 93-96.

30. Emms M, Tredwin CJ, Setchell DJ, Moles DR (2007) The effects of abutment wall height, platform size, and screw access channel filling method on resistance to dislodgement of cement-retained implant-supported restorations. J Prosthodont 16(1): 3-9. 
This work is licensed under Creative Commons Attribution 4.0 License DOI: 10.19080/ADOH.2018.09.555767

\section{Your next submission with Juniper Publishers} will reach you the below assets

- Quality Editorial service

- Swift Peer Review

- Reprints availability

- E-prints Service

- Manuscript Podcast for convenient understanding

- Global attainment for your research

- Manuscript accessibility in different formats

( Pdf, E-pub, Full Text, Audio)

- Unceasing customer service

Track the below URL for one-step submission https://juniperpublishers.com/online-submission.php 